\title{
The students' acceptance and use of their university's virtual learning environment
}

\author{
Mark Anthony Camilleri \\ University of Malta \\ Department of Corporate \\ Communication, Faculty of Media and \\ Knowledge Sciences \\ +3562340 3742 \\ mark.a.camilleri@um.edu.mt
}

\author{
Adriana Caterina Camilleri \\ Malta College of Arts, Sciences and \\ Technology \\ Institute of Community Services \\ +35623987100 \\ adriana.camilleri@mcast.edu.mt
}

\begin{abstract}
The proliferation of digital and mobile devices, including; smart phones and tablets has led policy makers and practitioners to include these ubiquitous technologies in the realms of education. A thorough review of the relevant literature suggests that both students as well as their course instructors are becoming increasingly acquainted with the adoption of education technologies in the higher educational context. Hence, this study explores the university students' readiness to engage with the virtual learning environment (VLE). The methodology has integrated measuring items that were drawn from the educational technology literature, including the unified theory of acceptance and use of technology, to better understand the students' perceptions towards VLE. It investigated whether they were influenced by their instructors or by fellow students to use VLE. The results suggest that most of the research participants were using this technology as they believed that it supported them in their learning outcomes. The findings also revealed that the students were not coerced by their course instructors or by other individuals to engage with VLE. Moreover, the university's facilitating conditions had a significant effect on the participants' usage of VLE. In conclusion, this contribution puts forward key implications to practitioners. It also clarifies the limitations of this study and proposes future research directions.
\end{abstract}

\section{Keywords}

Technology Acceptance Model, Theory of Planned Behavior, Unified Theory of Acceptance and Use of Technology, Mobile Learning, Virtual Learning Environment, University, Higher Education.

\section{CCS Concepts}

CCS $\rightarrow$ Human-centered computing $\rightarrow$ Ubiquitous and mobile computing $\rightarrow$ Ubiquitous and mobile computing design and evaluation methods

CCS $\rightarrow$ Human-centered computing $\rightarrow$ Ubiquitous and mobile computing

SAMPLE: Permission to make digital or hard copies of all or part of this work for personal or classroom use is granted without fee provided that copies are not made or distributed for profit or commercial advantage and that copies bear this notice and the full citation on the first page. To copy otherwise, or republish, to post on servers or to redistribute to lists, requires prior specific permission and/or a fee. Conference' City, State, Country. Copyright 2019 ACM 1-58113-000-0/00/0010 ...\$15.00. DOI: http://dx.doi.org/

\section{INTRODUCTION}

Many individuals hailing from different demographic and sociocultural backgrounds are continuously connected to the Internet via their mobile devices ([1]). They are increasingly becoming more experienced in the use of mobile apps as they engage with them regularly, on a daily basis ([2]). Most of these individuals perceive that these pervasive technologies are important for them, as they have improved the quality of their lives ([3]).

However, whilst mobile technologies may seem to be embedded in our lives, one cannot generalize that individuals are actively engaging with them in a similar manner. There may be different segments in society who for different reasons are still not availing themselves of the latest technologies or may not possess adequate and sufficient digital skills ([4]). Educators and policy makers may wrongly perceive that today's students are interested in the latest innovations. They may erroneously presume that all students are technically-adept. This may not always be the case. There may be young adults and adolescents who may not be as digitally skilled as their peers due to various factors ([2]). As a result, unskilled individuals may go unnoticed or undetected in our educational system. Moreover, academia may hold wrong perceptions, as they may stereotype the young individuals' preferred learning styles ([5]). The students may hold positive or negative attitudes towards different technologies as they possess different skills and cognitive abilities ([6], [7], [8]). Some researchers contend that although the young students are more exposed to information and communication technologies (ICTs) than their older counterparts, their predisposition to use education technologies remains a major issue that is still relatively underexplored in academia ([9], [10]). This argumentation suggests that the provision of education needs to adapt to today's realities.

A systematic review of the academic literature reported that the students were disappointed ([11]), dissatisfied ([12]), and disengaged ([13]) as they perceived that their educational institutions' teaching methods were outdated and irrelevant for them. Many academic contributions implied that several universities need to update their courses as they should improve their content and the modes of delivery ([14]). Educators and authorities should provide relevant learning resources to their students, as they will support them during their learning journey ([15]). Many teachers are increasingly using the educational technologies in their classrooms ([15], [16]). However, a few studies in post-compulsory, education suggest that students are not always willing to engage with the mentioned technologies ([17]). For instance, they may decide to use their smart phone or tablet for non-academic purposes. Notwithstanding, the use of digital and/or mobile learning technologies are not always available in all subjects and disciplines. Moreover, the individuals' 
disposition towards online (and mobile) learning varies considerably according to the demographic variables, including; age, gender, experience and nationality ([18]). Therefore, there may be different intrinsic motivations that can explain the rationale why students accept (or reject) specific educational technologies ([6], 19]).

\subsection{The Research Question}

This study builds on the foundations of the extant literature in academia as it explores the university students' attitudes and intentions to utilize the university's virtual learning environment (VLE). The individuals who are confident about using the digital media are more likely to adopt the university's mobile learning technologies that are readily available through VLE ([20], [21]). However, other factors, including the students' social influences as well as the respective institution's infrastructure and resources may trigger the students to avail themselves of particular learning technologies ([22]). Perhaps, the students may not be motivated to access VLE through their computer or via mobile applications (apps). Alternatively, they may not be encouraged by their course instructors to use the digital or mobile technologies to access their online resources.

In this light, this study has empirically validated a number of measuring constructs that were drawn from well-established theoretical frameworks in educational technology. Specifically, this research hypothesizes that there are significant and positive relationships between the university's facilitating conditions; the technology acceptance of mobile apps and the students' readiness to use them as learning resources. Moreover, this study presumes that the research participants could have been pressurized by their course instructor and/or by other individuals to engage with these technologies. These issues can possibly have positive and negative influences on their intentions to utilize the mobile apps in higher education.

\section{LITERATURE REVIEW}

\subsection{The Conceptual Development and the Formulation of Hypotheses}

Mobile learning can be implemented across different levels of education. However, it is highly relevant in the higher educational context, as the university students will already have their own mobile devices [23]. A thorough review of the literature suggests that there are a few empirical studies that have explored the students' readiness to use VLE technologies through a mobile device; although there are a number of studies that have investigated the users' acceptance of other educational technologies, including; digital learning resources, WebCT or Moodle systems ([15]). Several academic studies relied on valid and reliable measures that were drawn from the Theory of Reasoned Action, The Theory of Planned Behavior, the Technology Acceptance Model or the Unified Theory of Acceptance and Use of Technology, among others. Very often these theories suggested that the individuals' behavioral intention to use technological innovations is an important factor that determines whether they will actually utilize them [22].

Many studies have explored the relationship between the behavioral intention and actual usage of technology in different contexts ([24], [25], [26]). The individuals' intentions to use educational technologies could determine whether they will actually use (or reject) them ([23], [26], [27]). Hence, there is a strong relationship between the behavioral intention and actual usage ([28], [29]). This leads to the first hypothesis:

H1: There is a positive and significant relationship between the participants' behavioral intention to use the virtual learning environment and their active engagement with it.

The individuals' behavioral intention to use certain technologies could be determined by their attitude and is possibly conditioned by the perceived usefulness and ease of use of information systems ([8], [21], [23], [30]). Many academic studies have relied on the technology acceptance model (TAM)'s constructs to investigate the individuals' perceived usefulness and ease of use of technology ([30]). TAM has received empirical support in academia for being robust in predicting technology adoption in the realms of education ([31], [32]). The perceived ease of use is the degree to which a person believes that using a particular system would be free of effort ([30]). Therefore, the ease of use of technology has a significant direct effect on its usefulness ([23], [30]). In simple words, if the technology is easy to use the individuals can benefit from it. This leads to the second hypothesis:

$\mathrm{H} 2$ : There is a positive and significant relationship between the participants' perceived usefulness and their ease of use of the virtual learning environment.

The perceived usefulness of technology has often been defined as the degree to which a person believes that using a particular system would enhance his or her job performance [30]. Hence, the perceived usefulness is concerned with the expected overall impact of the technology on the individual's job performance (in terms of process and outcome). The usefulness of the technology has a direct effect on the individuals' intention to use it ([29]). Other researchers contended that the individuals' behavioral intention is affected by attitude toward usage, as well as by the direct and indirect effects of perceived usefulness and ease of use ([30]. [31]. [32]). This argumentation leads to the following hypotheses:

H3: There is a positive and significant relationship between the participants' perceived ease of use of the virtual learning environment and their attitudes towards it.

H4: There is a positive and significant relationship between the participants' perceived usefulness of the virtual learning environment and their attitudes towards it.

H5: There is a positive and significant relationship between the participants attitudes and intentions to utilize the virtual learning environment.

Other researchers recommended that TAM should be supplemented and extended by using the subjective norm construct ([10], [33]). Academic commentators argued that TAM should include additional variables that are related to both human and social change processes. Therefore, empirical studies have integrated elements from different theoretical models on technology acceptance and empirically validated them. They included external variables like subjective norms and facilitating conditions, among others, to examine the individuals' behavioral intentions to use educational technology ([29]. [32], [33]). Very often, the individuals' social influences construct was found to be a direct antecedent of behavioral intention to use the technology ([10], [22]) The individuals can be pressurized or influenced by their course instructors and/or by their peers to 
engage with the technologies. Moreover, the universities' infrastructure and the provision of training, support, and access to technology can facilitate the individuals' readiness to utilize the technology ([15], [33], [34]). The universities' facilitating conditions can be a direct antecedent for the individuals' intention to use the technology and/or for its usage. These arguments lead to the last hypotheses:

H6: There is a positive and significant relationship between the participants' social influences and their intention to utilize the virtual learning environment

H7: There is a positive and significant relationship between the university's facilitating conditions and the students' behavioral intentions to use the virtual learning environment.

H8: There is a positive and significant relationship between the university's facilitating conditions and the students' usage of the virtual learning environment.

\section{3: METHODOLOGY}

This study involved the administration of a survey questionnaire consisting of 26 multiple choice questions. The research participants were all registered students who were following full-time or parttime courses at the University of Malta (UM). The university registrar forwarded an email that informed the students about the rationale of this study. It also provided some guidelines on how to complete the questionnaire. The respondents could complete the questionnaire in less than ten minutes. They were expected to tick the most appropriate responses as they had to indicate their level of agreement with the survey's questions on a five-point Likert scale. Respondents were asked to indicate the strength of their agreement or disagreement with the statements. Responses were coded from 1 (strongly disagree) to 5 (strongly agree) with 3 signaling indecision.

The survey' measures were adapted from key theoretical underpinnings, including; the Technology Acceptance Model ([8], [30]), the Unified Theory of Acceptance and Use of Technology ([29], [33]) and the Theory of Planned Behavior ([7], [28], [34]). The questionnaire consisted of 26 multiple choice questions including three demographic ones. It explored the participants' perceived usefulness (4 items); perceived ease of use (4 items); attitudes towards the use ( 2 items) of the mobile learning technologies; social influences from other individuals, including educators and/or class mates (3 items); behavioral intentions (3 items); usage of mobile learning technologies ( 3 items), as well as the facilitating conditions at their university (4 items). In the last part of the questionnaire, the participants provided further information about their age and gender. They also indicated how long they had used the mobile learning technologies at UM (as they disclosed their experience with the mentioned technology).

\section{RESULTS \\ 4.1 The Research Participants}

The frequency table reported that there were seventy-five females and sixty-three males $(n=138)$ who participated in this study. The respondents were classified into five age groups $(18-23 ; 24-29 ; 30-$ $35 ; 36-41$ and over 42 years of age). The majority of the research participants were between 18 and 23 years of age $(n=93)$, followed by those aged between 24 and 29 years $(n=27)$. Most of the respondents $(n=48)$ indicated that they had been using VLE between 2-3 years. Almost a quarter of the research participants $(n=33,24 \%)$ have used this technology for less than a year. Most of the respondents were following courses in arts and humanities $(n=21)$, and this figure was closed followed by those who pursued courses in the realms of education $(n=19)$.

\subsection{The Descriptive Statistics}

The researcher assessed of the mean (M) scores, the standard deviations (SD) as well as the skewness and kurtoses of the responses. These values provided an indication of the students' perceptions towards the surveys' measuring items. The respondents indicated that they agreed with the questionnaire's statements, as there were high mean scores above the midpoint (3) that signaled a possible indecision. There was only one value (that represented a behavioral intention item) that was slightly below 3 (i.e. $\mathrm{M}=2.93$ ). Moreover, the SD indicated that there were small variances in the participants' responses. The values of the SD ranged from 0.743 to 1.31, that indicated a narrow spread around the mean. The kurtosis index indicated that there was a normal distribution in the dataset except for three items that belonged to the perceived ease of use measuring scale. The distribution of values was not always symmetrical as the skewness value was more than twice the standard error for several items. Moreover, the distribution had a long-left tail for most items, as suggested by the negative skewness results.

\subsection{The Principal Component Analysis}

The Kaiser Meyer Olkin test that measures the sampling adequacy reported a KMO of 0.654 . This value was acceptable; it was well above 0.5 (Field, 2005). Moreover, Bartlett's test of sphericity also revealed sufficient correlation in the dataset to run a principal component analysis (PCA) since $p<0.001$. Therefore, PCA was used to assess the construct validity. It explored the degree to which a construct differs from other constructs. At the same time, the data was compressed and reduced to obtain a factor solution of salient components that shared relevant similarities (and differences). The varimax rotation was used to reconstruct the seven composite factors. The factor loadings referred to the correlation between each retained factor and each of the original variables. Their values varied between -1 and +1 . They indicated the strength of relationship between a particular variable and the factor, in a way similar way to correlation. This study identified significant factor loadings of 0.5 or above. Table 1 presents the results of the principal component analysis. It features the seven extracted factor components, together with their respective eigenvalues, cumulative variance explained (\%) as well as the values of Cronbach's alpha.

Table 1. Results from the Principal Component Analysis

\begin{tabular}{|c|c|c|c|c|c|c|c|}
\hline \multirow[t]{2}{*}{ Component } & \multicolumn{3}{|c|}{ Initial Eigenvalues } & \multicolumn{3}{|c|}{$\begin{array}{l}\text { Rotation Sum of } \\
\text { Square Loadings }\end{array}$} & \multirow[t]{2}{*}{ Alpha } \\
\hline & Eig. & $\%$ of Var. & Cum. \% & Eig. & $\%$ of Var. & Cum. \% & \\
\hline \begin{tabular}{|l|} 
Perceived Ease \\
of Use
\end{tabular} & 4.800 & 25.468 & 25.468 & 3.226 & 17.117 & 17.117 & 0.92 \\
\hline \begin{tabular}{|l|}
2 Behavioral \\
Intention
\end{tabular} & 2.526 & 13.399 & 38.868 & 2.190 & 11.620 & 28.737 & 0.89 \\
\hline \begin{tabular}{|l}
3 Social \\
Influences
\end{tabular} & 2.202 & 11.681 & 50.549 & 1.852 & 9.823 & 38.560 & 0.86 \\
\hline \begin{tabular}{|l|}
4 Perceived \\
Usefulness \\
\end{tabular} & 1.597 & 8.471 & 59.020 & 2.000 & 10.611 & 49.171 & 0.85 \\
\hline \begin{tabular}{|l|}
5 Facilitating \\
Conditions
\end{tabular} & 1.305 & 6.921 & 65.941 & 2.386 & 12.658 & 61.828 & 0.82 \\
\hline 6 Attitude & .994 & 5.276 & 71.216 & 1.639 & 8.697 & 70.526 & 0.79 \\
\hline 7 Use & .922 & 4.892 & 76.109 & 1.052 & 5.583 & 76.109 & 0.76 \\
\hline
\end{tabular}

Typically, the variables with the highest correlation scores had mostly contributed towards the make-up of each component. The factor components accounted for $76 \%$ of the variance. The Cronbach's alpha assessed the reliability of the multi-item scales 
used in this study. The findings reported alpha values that were higher than 0.7 (i.e. the recommended threshold) for all constructs. The alpha coefficient ranged from 0.76 to 0.92 . These results suggest that the measures were reliable and internally consistent.

\subsection{Multivariate Regression Analysis}

The researchers relied on a regression analysis to investigate the hypothesized relationships of this study. We chose the stepwise procedure to identify the significant constructs, where the $\mathrm{p}$-value was less than the 0.05 benchmark Therefore, the insignificant variables were excluded without appreciably increasing the residual sum of squares. The first five hypotheses tested the hypothesized relationships appertaining to the Technology Acceptance Model, whilst the latter three hypotheses integrated other constructs, namely; social influences and facilitating conditions.

H1: The results from the regression analysis suggested that the individuals' behavioral intentions anticipated their usage of the VLE technology, where the adj. $\mathrm{r} 2=0.418$ and the $\mathrm{t}$ value $=2.235$ ). This relationship was significant as $\mathrm{p}=0.026$. $\mathrm{H} 2$ : There was also a positive and significant relationship between the students' perceived ease of use of the VLE technology and its perceived usefulness, where the adj. $\mathrm{r} 2=0.303$ and the $\mathrm{t}$ value $=1.904$. This relationship was significant as $p=0.043$. H3: The students' perceived ease of use of VLE had a positive and very significant effect $(p<0.001)$ on their attitudes towards this technology. The adj. $\mathrm{r} 2=0.157$ and the $\mathrm{t}$ value $=4.877$. H4: Similarly, the students' perceived usefulness of VLE had a positive and highly significant effect $(\mathrm{p}<0.001)$ on their attitudes towards it. The adj. $\mathrm{r} 2=0.163$ and $\mathrm{t}=3.984$. H5: Moreover, there was also a positive and significant relationship between the students' attitudes toward VLE and their behavioral intention to use it as adj. $\mathrm{r} 2=0.111$ and $\mathrm{t}$ value $=5.136$. The measurement of significance indicated a confidence level of $97 \%$ (where $p=0.03$ ).

H6: The individuals' social influences did not have a significant effect on the students' behavioral intention to use VLE. In this case the results were inconclusive as $p>0.05$. H7: There were no significant relationships between the university's facilitating conditions and the individuals' behavioral intentions to use VLE. Again, the findings were inconclusive as $p>0.05$. H8: Nevertheless, the facilitating conditions had a significant effect $(\mathrm{p}=0.02)$ on the students' usage of VLE, where adj. $\mathrm{r} 2=0.435$ and $\mathrm{t}$ value $=13.608$.

\section{CONCLUSIONS AND IMPLICATIONS}

This study has validated previous empirical work in academia as it explored the research participants' technology acceptance to use VLE. The findings revealed the factors that were having the most significant effect on the students' engagement with the mentioned technology in a higher educational institution from southern Europe. The results were congruent with other recent studies that have explored the use of technology in higher education. The descriptive statistics indicated that the participants perceived the VLE technology as easy to use. Moreover, there were high mean scores that represented the university's facilitating conditions and the individuals' usage of technology. The results from the principal component analysis also revealed that the most determining factors behind the students' engagement with this learning technology was its simplicity and ease of use. This issue probably had an effect on the participants' intention to use the technology in the future. This was clearly evidenced in the factor analysis.

The regression analysis clearly evidenced the positive and significant relationships of the tested hypotheses. The perceived usefulness was significantly corelated with the perceived ease of use. Both constructs were the antecedents of attitude toward use. Moreover, the latter construct preceded behavioral intention. Notwithstanding, this study found a highly significant relationship between the university's facilitating conditions and the students' utilization of VLE. On the other hand, this study reported that there was no significant relationship between facilitating condition and behavioral intention. This study also indicated that there was no positive and significant relationship between the students' social influences and their intention to use VLE. Similar findings reported that the social influences had a negative impact on the individuals' behavioral intentions to utilize VLE. However, other researchers found that the students are influenced by their course instructors to use the university's technologies in different contexts ([34], [35]). In conclusion, this research has shown that VLE is increasingly being utilized by many students hailing from various faculties. The students themselves indicated that they considered this educational technology as necessary to improve their learning journey. Hence, there is scope for the university educators and policy makers to create and adopt VLE technologies in addition to traditional teaching methodologies, in order to deliver quality education.

\subsection{Future Research Avenues}

The researcher relied on a linear regression analysis to explore the students' acceptance and usage of VLE in higher education. The number of respondents was more than sufficient to draw significant inferences from the results. However, further research is necessary to identify the factors that facilitate or hinder the students' engagement with these education technologies. A qualitative study could reveal the students' in-depth opinions and personal experiences on VLE. Future studies can investigate the strengths and weaknesses of using VLE for specific subjects. Other research can shed more light on the design, structure and content of VLE as this technology can be accessed through mobile apps, including smartphones and tablets. Moreover, longitudinal studies could possibly provide a better understanding of the students' engagement with VLE technologies in the long run. The students' attitudes and perceptions towards VLE can change over time, particularly as they become experienced users of this technology.

\section{ACKNOWLEDGMENTS}

We express my gratitude to the University of Malta's Research Ethics Committee and to the registrar for allowing us to gather our data from the university's student population.

\section{REFERENCES}

1. Camilleri, M. A. 2018. The SMEs' technology acceptance of digital media for stakeholder engagement. Journal of Small Bus. \& Ent. Dev. 26, 4, 504-521.

2. Henderson, M., Selwyn, N. and Aston, R. 2017. What works and why? Student perceptions of 'useful'digital technology in university teaching and learning. Stud. in Higher Educ. 42, 8, 1567-1579.

3. Camilleri, M. A. 2018. The promotion of responsible tourism management through digital media. Tour. Planning. \& Dev. 15, 6, 653-671.

4. Betts, L. R. and Spenser, K. A. 2017. People think it's a harmless joke": young people's understanding of the impact of technology, digital vulnerability and cyberbullying in the United Kingdom. Journal of Children \& Med. 11, 1, 20-35.

5. Truong, H. M. 2016. Integrating learning styles and adaptive elearning system: Current developments, problems and opportunities. Comp. in Human Behav. 55, 1185-1193. 
6. Camilleri, A. C. and Camilleri, M. A. 2019. The Students Intrinsic and Extrinsic Motivations to Engage with Digital Learning Games. In Shun-Wing N.G., Fun, T.S. and Shi, Y. (Eds.) 5th International Conference on Education and Training Technologies (ICETT 2019), Seoul, South Korea.

7. Cheon, J., Lee, S., Crooks, S. M. and Song, J. 2012. An investigation of mobile learning readiness in higher education based on the theory of planned behavior. Comp. \& Educ. 59, 3, 1054-1064.

8. Camilleri, A. C. and Camilleri, M. A. 2019. The students' perceived use, ease of use and enjoyment of educational Games at Home and at School. 13th Annual International Technology, Education and Development Conference. International Academy of Technology, Education and Development (INTED2019), Valencia, Spain.

9. Fabian, K., Topping, K. J. and Barron, I. G. 2018. Using mobile technologies for mathematics: effects on student attitudes and achievement. Educ.Tech.Res. \& Dev. 66, 5, 1119-1139.

10. Camilleri, M. A. and Camilleri, A. C. 2019. The Students' Readiness to Engage with Mobile Learning Apps. Interactive Tech. \& Smart Educ. https://www.emerald.com/insight/content/doi/10.1108/ITSE06-2019-0027/full/html

11. Camilleri, M. A. and Camilleri, A. C. 2019. Student-Centred Learning through Serious Games. 13th Annual International Technology, Education and Development Conference (INTED2019), Valencia, Spain.

12. Wolbring, T. and Treischl, E. 2016. Selection bias in students' evaluation of teaching. Res. in Higher Educ. 57, 1, 51-71.

13. Jang, H., Kim, E. J. and Reeve, J. 2016. Why students become more engaged or more disengaged during the semester: A selfdetermination theory dual-process model. Learng \& Instr. 43, 27-38.

14. Fang, Z. 2014. Preparing content area teachers for disciplinary literacy instruction: The role of literacy teacher educators. Journal of Adol. \& Adult Liter. 57, 6, 444-448.

15. Camilleri, M. A. and Camilleri, A. C. 2017. Digital learning resources and ubiquitous technologies in education. Tech. Know. \& Learng, 22, 1, 65-82.

16. Tondeur, J., Van Braak, J., Ertmer, P. A. and OttenbreitLeftwich, A. 2017. Understanding the relationship between teachers' pedagogical beliefs and technology use in education: a systematic review of qualitative evidence. Educ. Tech. Res. \& Dev. 65, 3, 555-575.

17. Deng, L. and Tavares, N. J. 2013. From Moodle to Facebook: Exploring students' motivation and experiences in online communities. Comp. \& Educ. 68, 167-176.

18. Wang, Y. S., Wu, M. C. and Wang, H.Y. 2009. Investigating the determinants and age and gender differences in the acceptance of mobile learning. Brit. Journal of Educ. Tech. 40, $1,92-118$

19. Wang, J., Yu, W. C. W. and Wu, E. 2013. Empowering Mobile Assisted Social E-Learning: Students' Expectations and Perceptions, World Journal of Educ. 3, 2, 59-70.

20. Camilleri, A. C. and Camilleri, M. A. 2019. Mobile Learning via Educational Apps: An Interpretative Study. In Shun-Wing N. G., Fun, T. S. and Shi, Y. (Eds.) 5th International Conference on Education and Training Technologies (ICETT 2019). Seoul, South Korea.

21. Camilleri, M. A. and Camilleri, A. C. 2017. The Technology Acceptance of Mobile Applications in Education. In Sánchez, I.A. and Isaias, P. (Eds) 13th International Conference on
Mobile Learning, International Association for Development of the Information Society. IADIS Proceedings, 41-48, Budapest, Hungary.

22. Teo, T. and Zhou, M. 2014. Explaining the intention to use technology among university students: a structural equation modeling approach. Journal of Comp. in Higher Educ. 26, 2, 124-142.

23. Camilleri, M. A. and Camilleri, A. C. 2017. Measuring the educators' behavioural intention, perceived use and ease of use of mobile technologies. In Wood, G. (Ed) Re-connecting management research with the disciplines: Shaping the research agenda for the social sciences, British Academy of Management Proceedings, University of Warwick, UK.

24. So, S. 2016. Mobile instant messaging support for teaching and learning in higher education. The Internet and Higher Educ. 31, $32-42$.

25. Jeong, H. I. and Kim, Y. 2017. The acceptance of computer technology by teachers in early childhood education. Interactive Learng Env. 25, 4, 496-512.

26. Van Raaij, E. M. and Schepers, J. J., 2008. The acceptance and use of a virtual learning environment in China. Comp. \& Educ. $50,3,838-852$.

27. Jones, C. and Hosein, A., 2010. Profiling university students' use of technology: where is the NET generation divide? The Int. Journal of Tech. Know. \& Soc. 6,3, 43-58.

28. Ajzen, I., 1991. The theory of planned behavior. Org. Behav. \& Hum. Dec. Proc. 50, 2, 179-211.

29. Venkatesh, V., Morris, M. G., Davis, G. B., and Davis, F. D. 2003. User acceptance of information technology: Toward a unified view. MIS Quart. 27, 3, 425-478.

30. Davis, F.D. 1989. Perceived usefulness, perceived ease of use, and user acceptance of information technology. MIS Quart. $13,3,319-340$.

31. Cheung, R. and Vogel, D. 2013. Predicting user acceptance of collaborative technologies: An extension of the technology acceptance model for e-learning. Comp. \& Educ. 63, 160-175.

32. Teo, T. 2009. Modelling technology acceptance in education: A study of pre-service teachers. Comp. \& Educ. 52, 2, 302-312.

33. Venkatesh, V., Thong, J. Y., and Xu, X. 2012. Consumer acceptance and use of information technology: extending the unified theory of acceptance and use of technology. MIS Quart. $36,1,157-178$.

34. Teo, T. and Noyes, J. 2014. Explaining the intention to use technology among pre-service teachers: a multi-group analysis of the Unified Theory of Acceptance and Use of Technology. Interactive Learng Env. 22, 1, 51-66.

35. Camilleri, M. A. and Camilleri, A. C. 2017. The Students' Perceptions of Digital Game-Based Learning. In Pivec, M. and Grundler, J. (Ed.) 11th European Conference on Games Based Learning, ECGBL Proceedings, 52-62, H Joanneum University of Applied Science, Graz, Austria. 
Authors' background

\begin{tabular}{|l|l|l|l|}
\hline Your Name & Title* & Research Field & Personal website \\
\hline Mark Anthony Camilleri & Associate Professor & $\begin{array}{l}\text { Digital Media } \\
\text { Technology Acceptance }\end{array}$ & $\underline{\text { https://www.um.edu.mt/profile/markacamilleri }}$ \\
\hline $\begin{array}{l}\text { Adriana Caterina } \\
\text { Camilleri }\end{array}$ & Senior Lecturer & $\begin{array}{l}\text { Education Technology } \\
\text { Psychology }\end{array}$ & $\underline{\underline{\text { https://mt.linkedin.com/in/adriana-camilleri- }}}$ \\
\hline
\end{tabular}

